\title{
Uranium-234, uranium-235 and uranium-238 in soil near Siberian Chemical Enterprises (Tomsk-7, Seversk)
}

\author{
A.D. Gedeonov ${ }^{1}$, I.V. Kolchin ${ }^{1}$, A.I. Malishkin ${ }^{2}$ and G.S. Andreev ${ }^{2}$ \\ ${ }^{1}$ Research-Industrial Association V. G. Khlopin Radium Institute, 1 Roentgena St., \\ 197101 St. Petersburg, Russia \\ 2 Siberian Chemical Enterprises, 1 Kurchatov St., Seversk, 636000 Tomsk Region, Russia
}

\begin{abstract}
Siberian Chemical Enterprises (SCE), located $15 \mathrm{~km}$ from the city of Tomsk downstream the Tom river, has been put into operation in 1953 and has become one of the main uranium and plutonium production facilities in the world. In this paper the results are repoted on the concentrations of uranium-234, uranium-235 and uranium-238 in soil near the SCE. Experimental results on uranium isotopes determination in soil around the SCE on-site and off-site are discussed.
\end{abstract}

\section{INTRODUCTION}

Siberian Chemical Enterprises (SCE), located $15 \mathrm{~km}$ from the city of Tomsk downstream the Tom river, has been put into operation in 1953 and become one of the main uranium and plutonium production facilities in the world. SCE personnel and their families live in the former Tomsk-7, now the town of Seversk, located near the southern border of the SCE site. The dominant potential sources of environmental uranium are radiochemical plant, enrichment plant, metallurgical plant, solid and liquid radioactive waste storage area (ponds, pulp storages and tanks). Control on radiation situation around SCE is carried out in the sanitary zone and zone of observation. In 2003 the SCE adopted a new radiochemical method of uranium-234, uranium-235 and uranium-238 determination in environmental samples (soils, sediments, snow, air dust et. al.). Since 2004 SCE together with the RIA "V. G. Khlopin Radium Institute" began monitoring of uranium isotopes in soil near Siberian Chemical Enterprises with the above mentioned procedure. In this paper the results are reported for the years 2004-2006 on the concentration of the uranium isotopes in soil at stationary sampling stations around the SCE. Also background and local on-site and off-site uranium isotopes concentrations in soil near the Siberian Chemical Enterprises were measured.

\section{MATERIALS AND METHODS}

\subsection{Sampling}

Three of the 18 sampling stations are located at the SCE sanitary zone, two - in the town Seversk and the other 12 - off-site (see Fig. 1). Soil samples for background uranium isotopes concentration measurements were collected at the sampling station "Pobeda" $50 \mathrm{~km}$ southwest of the SCE (NE wind recurrence $10 \%$ ) with prevailing wind directions S (40\%) and SW (17\%).

\subsection{Analysis}

Soil samples were processed in accordance with the standard procedure "Uranium-234, 235, 238. Radiochemical Method for Determination of Isotopic Content in Environmental Samples", certified by the Mendeleyev Institute of Metrology (St. Petersburg, Russia). This procedure incorporates total 


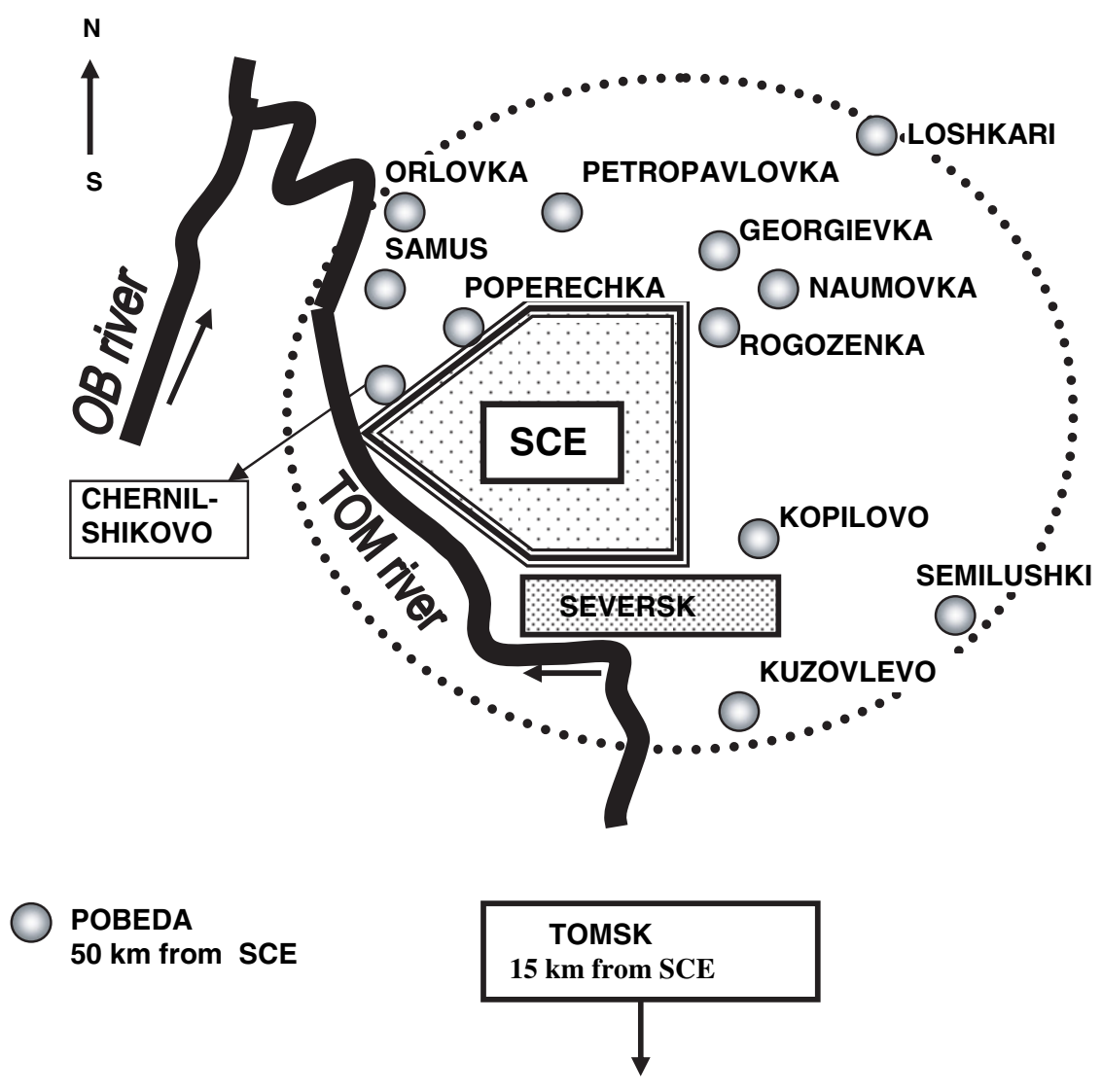

Figure 1. Soil sampling location in the vicinity of Siberian Chemical Enterprises.

dissolving of samples in mixture of mineral acids, uranium concentration on $\mathrm{Fe}(\mathrm{OH})_{3}$, purification on anionic resin AV-17 and preparation of the thin alpha-spectrometric source. Air dried soil samples were powdered and sieved. Five-gram aliquots with particles of size up to $1 \mathrm{~mm}$ were taken for the analysis. After ashing $\left(\mathrm{t}=600^{\circ} \mathrm{C}\right)$ samples were processed according to the above mentioned procedure. ${ }^{232} \mathrm{U}$ was added to the soil sample before ashing as tracers to control the radiochemical yield. At a final stage uranium fraction was evaporated with tetraethylene glycol and fired on silicon discs. Alpha-spectra of the samples were registered with a grid ionization chamber spectrometer NU -114 and $1000 \mathrm{~mm}^{2}$ silicon surface barrier detector. The samples were counted for 3 days. The radioanalytical technique was validated with respect to the IAEA Reference Material IAEA-326 and IAEA-300.

\section{RESULTS AND CONCLUSIONS}

Experimental results of uranium isotopes activity concentrations measurements in soil at sampling stations in the sanitary zone and zone of observation (Georgievka, Kuzovlevo, Chernilshikovo, Petropavlovka, Kopilovo, Samus, Rogozenka, Naumovka, Loshkari, Poperechka, Semilushki and Orlovka) around the SCE are presented in Table 1.

These results show that the content of ${ }^{238} \mathrm{U}$ and ${ }^{234} \mathrm{U}$ in samples from the zone of observation within the error of measurements is not higher than the average background concentration of these natural radioactive isotopes in soils $(21 \mathrm{~Bq} / \mathrm{kg}$ according to Wedepohl [1] and $35 \mathrm{~Bq} / \mathrm{kg}$ by data published in 
Table 1. ${ }^{238} \mathrm{U},{ }^{235} \mathrm{U}$ and ${ }^{234} \mathrm{U}$ activity concentrations in soil (depth $0-5 \mathrm{~cm}$ ) in vicinity of the Siberian Chemical Enterprises.

\begin{tabular}{|c|c|c|c|c|}
\hline \multirow[t]{2}{*}{ Year } & \multirow[t]{2}{*}{ Sampling location } & \multicolumn{3}{|c|}{ Activity concentration, $\mathrm{Bq} * \mathrm{~kg}^{-1} \pm \mathrm{SD}$} \\
\hline & & ${ }^{238} \mathrm{U}$ & ${ }^{235} \mathrm{U}$ & ${ }^{234} \mathrm{U}$ \\
\hline \multirow{9}{*}{2004} & Seversk (Iglakovo) & $16,7 \pm 0,7$ & $<0,5$ & $19,9 \pm 0,8$ \\
\hline & Seversk (Chekist) & $11,7 \pm 0,4$ & $\leq 0,5$ & $11,3 \pm 0,4$ \\
\hline & Georgievka & $8,3 \pm 0,4$ & $\leq 0,5$ & $10,1 \pm 0,4$ \\
\hline & Chernilshikovo & $13,1 \pm 0,5$ & $<0,5$ & $13,7 \pm 0,5$ \\
\hline & Kopilovo & $16,5 \pm 0,6$ & $\leq 0,5$ & $18,0 \pm 0,6$ \\
\hline & Samus & $9,6 \pm 0,4$ & $<0,5$ & $9,8 \pm 0,4$ \\
\hline & $32 \mathrm{~km}$ Tomsk - Samus road (SCE sanitary zone) & $11,9 \pm 1,1$ & $<0,6$ & $12,2 \pm 1,1$ \\
\hline & $4 \mathrm{~km}$ south-east from Chernilshikovo (SCE sanitary zone) & $19,5 \pm 0,8$ & $\leq 0,9$ & $19,4 \pm 0,8$ \\
\hline & Rogozenka & $22,9 \pm 1,0$ & $\leq 1,0$ & $22,2 \pm 1,0$ \\
\hline \multirow{11}{*}{2005} & $500 \mathrm{~m}$ from Enrichment plant (SCE sanitary zone) & $21,9 \pm 0,6$ & $\leq 1,0$ & $26,5 \pm 0,7$ \\
\hline & Naumovka & $23,7 \pm 0,9$ & $\leq 1,0$ & $24,0 \pm 0,8$ \\
\hline & Loshkari & $25,0 \pm 1,1$ & $\leq 1,0$ & $27,3 \pm 1,1$ \\
\hline & Georgievka & $11,1 \pm 1,3$ & $\leq 1,0$ & $12,4 \pm 1,3$ \\
\hline & Chernilshikovo & $14,0 \pm 1,3$ & $<1,0$ & $13,3 \pm 1,3$ \\
\hline & Seversk (Iglakovo) & $23,6 \pm 0,9$ & $\leq 1,5$ & $24,3 \pm 0,9$ \\
\hline & Poperechka & $12,2 \pm 0,8$ & $<0,8$ & $13,3 \pm 0,8$ \\
\hline & Kuzovlevo & $20,8 \pm 1,2$ & $\leq 2,0$ & $21,2 \pm 1,2$ \\
\hline & Semilushki & $26,2 \pm 1,3$ & $\leq 2,0$ & $26,1 \pm 1,3$ \\
\hline & Petropavlovka & $14,5 \pm 0,8$ & $\leq 2,0$ & $14,2 \pm 0,8$ \\
\hline & Orlovka & $13,0 \pm 1,3$ & $\leq 0,9$ & $12,5 \pm 1,3$ \\
\hline \multirow[t]{2}{*}{2006} & Rogozenka & $20,6 \pm 0,4$ & $\leq 1,0$ & $21,1 \pm 0,4$ \\
\hline & Pobeda (background) & $10,6 \pm 0,9$ & $\leq 0,5$ & $10,0 \pm 0,9$ \\
\hline
\end{tabular}

UNSCEAR [2]). It was founded that concentrations of ${ }^{238} U$ and ${ }^{234} U$ in soils collected on the territory of Seversk in Iglakovo and Chekist sample stations also do not exceed the natural level. The same result was received for soils collected in the western and eastern borders of the SCE near Chernilchikovo and $32 \mathrm{~km}$ of the Tomsk - Samus road (see Table 1). The content of ${ }^{238} \mathrm{U}$ in the soil sample collected at the distance of $500 \mathrm{~m}$ from Enrichment plant is not higher than natural level of uranium-238. The ${ }^{234} \mathrm{U} /{ }^{238} \mathrm{U}$ isotope ratio equal to 1,21. However Minteer et al [3] experimentally proved that alpha-spectrometric measurements of ${ }^{234} \mathrm{U}$ and ${ }^{238} \mathrm{U}$ ratio in the range from 1,03 to 1,29 may be due to the availability of the natural uranium only. Thus, the soils samples collected at 18 sampling stations in the sanitary zone of the SCE, zone of observation and on the territory of Seversk were analyzed. The study has shown that concentrations of ${ }^{238} \mathrm{U},{ }^{235} \mathrm{U}$ and ${ }^{234} \mathrm{U}$ isotopes in all soil samples were at the level of the natural content of these isotopes in soils.

\section{References}

[1] Wedepohl K.H., Geochim. acta 59 (1995) 1217-1232.

[2] UNSCEAR 2000 report to the General Assembly. Sources and effects of ionizing radiation. Volume I: Sources. Annex B: Exposure from natural radiation sources (United Nations Scientific Committee on the Effects of Atomic Radiation, New York, 2000) p. 34.

[3] Minteer M., Winkler P., Wyatt B., Moreland S., Jonson J. and Winters T., Health Physics 92 (2007) 488-495. 
